\title{
MODEL SEM-PLS TERBAIK UNTUK EVALUASI PEMBELAJARAN MATEMATIKA DISKRIT DENGAN LMS
}

\section{Best SEM-PLS Model to Evaluate Discrete Mathematics Learning with LMS}

\author{
Novi Mardiana ${ }^{1 *}$, Ahmad Faqih ${ }^{2}$ \\ ${ }^{1,2}$ Jurusan Teknik Informatika, STMIK IKMI Cirebon \\ Jln. Perjuangan 10B, Majasem, Cirebon, 45134, Indonesia \\ e-mail:1*nov.mardiana@gmail.com ; 2ahmadfaqih367@gmail.com
}

Corresponding author*

\begin{abstract}
Abstrak
Penelitian tentang penggunaan Structural Equation Modeling-Partial Least Square (SEM-PLS) terkait Learning Management System (LMS) telah berkembang sangat pesat. Namun, dalam penelitian-penelitian tersebut tidak dijelaskan bagaimana memilih model terbaik untuk mengevaluasi hubungan antar variabel laten dalam model. Penelitian ini bertujuan untuk memilih model SEM-PLS terbaik terkait evaluasi pemanfaatan LMS dalam pembelajaran Matematika Diskrit berdasarkan kriteria nilai $\mathrm{Q}^{2}, \mathrm{AIC}, \mathrm{AICu}$, AICc, BIC, HQ, dan HQc. Data diperoleh dari survei terhadap 109 mahasiswa semester 3 yang mengambil mata kuliah Matematika Diskrit di STMIK IKMI Cirebon menggunakan 5 variabel laten. Model Utama dibentuk berdasarkan semua variabel laten penelitian dan dievaluasi dengan tahapan 1) PLS-Algorhtm, 2) Bootstrapping dan 3) Blindfolding. Berdasarkan Model Utama tersebut, 16 model alternatif dibentuk dengan variabel manifest yang sama dengan Model Utama. Model terbaik ditentukan berdasarkan nilai $\mathrm{Q}^{2}$ paling besar dan krtieria nilai AIC, AICu, AICc, BIC, HQ dan HQc paling minimal. Hasil kajian menunjukan bahwa Model Utama lebih baik berdasarkan nilai $\mathrm{Q}^{2}$ dibandingkan dengan model lainnya dalam penelitian ini. Hasil berbeda diperoleh jika digunakan kriteria AIC, AICu, AICc, $\mathrm{BIC}, \mathrm{HQ}$ dan $\mathrm{HQc}$, dimana Model $\mathrm{C}_{2}$ dan $\mathrm{B}_{2}$ adalah model terbaik berdasarkan kriteria tersebut.
\end{abstract}

Kata Kunci : Kriteria Pemilihan Model, Pemilihan Model, SEM-PLS

\begin{abstract}
Research on the use of Structural Equation Modelling-Partial Least Square (PLS-SEM) related to Learning Management System LMS has developed very rapidly. However, in these studies, it was not explained how to choose the best model used to evaluate the relationship among latent variables in the model. This study aims to select the best SEM-PLS model related to evaluating the use of LMS in Discrete Mathematics learning based on the criteria of $Q^{2}, A I C, A I C u, A I C c, B I C, H Q$, and $H Q c$. Data obtained from a survey of 109 3rd semester students who took Discrete Mathematics courses at STMIK IKMI Cirebon using 5 latent variables. The Main Model is formed based on all research latent variables and evaluated by stages 1) PLS-Algorithm, 2) Bootstrapping and 3) Blindfolding. Based on the Main Model, 16 alternative models are created with the same manifest variables as the Main Model. The best model is determined based on the highest $Q^{2}$ value, and the least $A I C, A I C u, A I C c, B I C, H Q$ and $H Q c$ values. The results of the study show that the Main Model is better based on the $Q^{2}$ value compared to other models in this study. Different results are obtained if the AIC, AICu, AICc, BIC, $H Q$ and $H Q c$ criteria are used, where Model $C_{2}$ and $B_{2}$ are the best models based on these criteria.
\end{abstract}

Keywords: Model Selection, Model Selection Criteria, SEM-PLS 


\section{PENDAHULUAN}

Dalam banyak penelitian terkait SEM-PLS, disajikan model tertentu untuk dievaluasi model pengukuran dan model strukturalnya, tanpa menginformasikan bagaimana model yang disajikan tersebut dipilih dan digunakan untuk menjelaskan data populasi. Hingga saat ini masih sedikit kajian mengenai pemilihan model SEM dalam konteks PLS, khususnya dalam mengevaluasi pembelajaran yang menggunakan Learning Management System. Penelitian [1] menggunakan nilai $f^{2}$ dan $R^{2}$, sementara [2] membandingkan nilai $R^{2}$, dan [3] menggunakan nilai koefisien jalur untuk menentukan model terbaik yang menggambarkan populasi. Kajian [4] dan [5] menyajikan beberapa alternatif cara memilih model dalam konteks PLS sehingga peneliti tidak salah dalam mengintrepretasikan data. Dalam kajian tersebut dinyatakan bahwa nilai $Q^{2}$ dalam konteks PLS dapat digunakan sebagai parameter untuk memilih "true model". Dalam kajian yang sama, kriteria lain seperti AICu, BIC, HQ dan HQc lebih direkomendasikan sebagai indeks untuk memilih model terbaik. Model terbaik dalam konteks ini adalah model yang memiliki keseimbangan antara kompleksititas dan akurasi kemampuan prediksi [5].

Adapun model yang digunakan dalam penelitian ini adalah adopsi dari model Technology Acceptance Model) TAM [6] dan model Delone-Mclean [7]. Variabel Perceived Ease of Use (PE), Perceived of Usefulness (PU) diadopsi dari model TAM, sementara variabel Interest to Learning (IL) adaptasi dari variabel Attitude Toward Use dan Quality of Learning (QL) adalah adaptasi dari variabel Net Benefit pada Model Delone-McLean. Pada penelitian ini, ditambahkan pula variabel Relevancy of Content (RCL) pada model untuk melihat pula keterkaitannya dengan variabel IL dan QL. Model Utama yang digunakan pada penelitian ini disajikan pada Gambar 1.

Model TAM telah digunakan dalam banyak penelitian untuk melihat tingkat penerimaan teknologi dalam berbagai bidang. Sementara itu, model Delone-Mclean telah banyak diterapkan untuk mengevaluasi keberhasilan dan efektifitas penerapan sebuah sistem informasi. Model Delone-McLean digunakaan sebagai alat untuk mengukur, menilai dan mengevaluasi keberhasilan dalam pembelajaran daring di pendidikan tinggi [8]. Penelitian [9] mengkaji efek LMS, self efficacy dan self regulated learning terhadap kepuasan mahasiwa dan efektifitas sistem dalam proses pembelajaran.

Kajian terkait pemanfaatan LMS dalam proses pembelajaran di pendidikan tinggi telah banyak dilakukan sebagai upaya peningkatan kualitas dalam proses pembelajaran dan analisa terkait inovasiinovasi yang dapat dilakukan dalam proses pembelajaran di perguruan tinggi. Kajian tersebut diantaranya menyajikan hasil mengenai efek pemanfaatan LMS tehadap capaian hasil belajar mahasiswa di pendidikan tinggi [10]. Penelitian [11] menyatakan bahwa pemanfaatan LMS dalam proses pembelajaran pada era digital berperan penting untuk mempertahankan minat belajar dan keterikatan mahasiswa pada proses pembelajaran yang berkesinambungan.

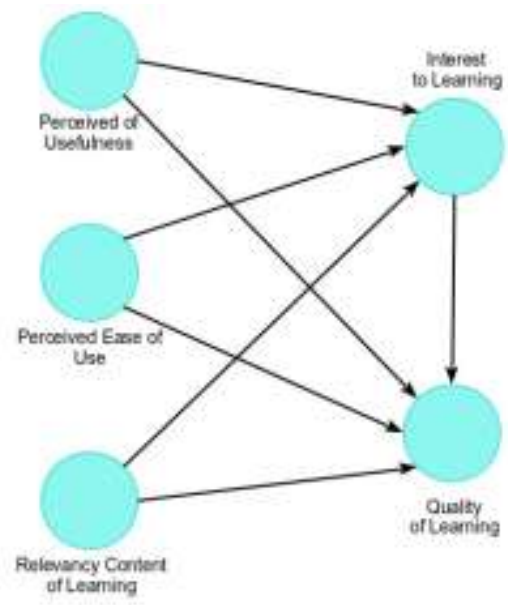

Gambar 1. Model Utama

Lebih jauh, terdapat 4 hal yang paling penting yang menentukan kepuasan mahasiswa dalam menggunakan LMS dalam proses pembelajaran di perguruan tinggi yaitu kualitas, kuantitas dan variasi konten pembelajaran [12]. Dalam penelitian tersebut diperoleh hasil bahwa, konten sangat berpengaruh atas persepsi mahasiswa terhadap LMS. Penelitian [13] berbicara tentang kualitas dari konten multimedia 
dalam LMS yang berpengaruh terhadap penguasaan pengetahuan pengguna LMS. Berdasarkan penelitian [14], faktor yang mempengaruhi efektifitas penggunaan LMS adalah kelengkapan dan kebaruan konten pembelajaran, kemudahan penggunaan dan akses LMS serta respon instruktur. Belum banyak penelitian yang mengkaji hubungan antara kualitas LMS dan pencapaian akhir dari proses pembelajaran. Kepuasan mahasiwa menjadi faktor penentu partisipasi aktifnya dalam pembelajaran dengan LMS dan berkorelasi positif terhadap quality of learning [15]. Sementara [16] menyimpulkan bahwa LMS mampu memotivasi siswa untuk meningkatkan hasil belajarnya.

Tujuan akhir dari penelitian ini adalah memilih model terbaik berdasarkan kriteria SEM-PLS yaitu $\mathrm{Q}^{2}$ dan kriteria pemilihan model lain yaitu nilai : AIC, AICu, AICc, BIC, HQ dan HQc, sehingga model yang dipilih mampu mendeskripsikan hubungan antar variabel laten dengan lebih akurat. Penelitian ini menggunakan kasus pemanfaatan LMS dalam proses pembelajaran Matematika Diskrit.

\section{METODE PENELITIAN}

Penelitian ini menggunakan variabel Perceived of Usefulness (PU), Perceived Ease of Use (PE), Relevansi Content of Learning ( $R C L$ ) sebagai variabel eksogen dan Interest of Learning (IL) dan Quality of Leaning $(Q L)$ sebagai variabel endogen. Variabel laten adalah variabel yang tidak dapat diukur secara langsung dimana terdapat 2 variabel laten yaitu variabel endogen (dipengaruhi) dan eksogen (mempengaruhi). Masing-masing variabel laten dijelaskan oleh beberapa variabel manifest. Variabel manifest adalah variabel yang digunakan untuk menjelaskan variabel laten. Variabel manifest berupa indikator yang diturunkan menjadi item-item pertanyaan dalam kuisioner yang terkait dengan variebal laten masing-masing. Pada penelitian ini, variabel PU, PE dan QL memiliki 7 variabel manifest, RCL memiliki 9 variabel manisfest, dan IL memiliki 10 variabel manifest.

Variabel PU menggambarkan manfaat dari LMS dalam proses pembelajaran Matematika Diskrit. Variabel PE mendeskripsikan kemudahan dalam menggunakan LMS sebagai alat bantu dalam proses pembelajaran dan variabel IL menggambarkan minat belajar mahasiswa setelah LMS digunakan untuk mendukung proses pembelajaran. Selanjutnya, variabel RCL adalah variabel yang menyatakan kualitas dan relevansi dari konten serta materi pembelajaran yang disediakan dalam LMS. Variabel IL menggambarkan minat mahasiswa dalam pembelajaran baik karena LMS maupun konten pembelajaran yang disediakan dalam LMS. Variabel QL menggambarkan persepsi mahasiswa terhadap kualitas hasil akhir pembelajaran

Data yang dipakai dalam penelitian ini diperoleh dari ouput kuesioner yang telah diuji validitas dan reliabilitasnya. Uji valididtas dilakukan menggunakan uji Pearson Product Moment dan uji realibilitas menggunakan nilai Alpha Cronbach. Uji tersebut melibatkan 50 mahasiswa semester 3 angkatan 2016 yang telah menyelesaikan perkuliahan Matematika Diskrit dengan LMS sebagai sistem pendukung. Berdasarkan hasil uji validitas dari 53 variabel manifest pada 5 variabel laten, terdapat 40 variabel manifest yang valid dengan nilai $r_{\text {hitung }}$ masing-masing item $>r_{\text {tabel }}=0,2353$. Sementara itu, hasil uji reliabilitas dengan Alpha Cronbach, diperoleh nilai alpha 0,92. Dengan demikian dapat dikatakan instrumen telah valid dan reliabel sehingga dapat digunakan untuk pengambilan data pada responden yang akan diuji. Responden penelitian ini adalah mahasiswa semester 3 angkatan 2017 yang menggunakan LMS dalam proses pembelajaran Matematika Diskrit. Terdapat 109 data responden yang dapat digunakan untuk dianalisa dari 114 responden yang mengisi kuesioner. Penelitian dilakukan di Prodi Teknik Informatika STMIK IKMI Cirebon.

Penelitian ini menggunakan metode SEM-PLS untuk memodelkan hubungan antar variabel-variabel laten yang kompleks. Berdasarkan data hasil tabulasi kuesioner, variabel-variabel laten dimodelkan menggunakan software SmartPLS free trial. Selanjutnya model awal dinamakan sebagai Model Utama. Berdasarkan Model Utama yang sudah dievaluasi, dibentuk model lain yang berbeda konfigurasi hubungan antar variabel latennya sebanyak 16 model. Model alternatif ini menggunakan variabel-variabel manifest yang persis sama dengan Model Utama. Pemilihan model didasarkan pada hubungan variabel laten dalam model struktural. Semua model alternatif yang dihasilkan dievaluasi model pengukurannya, dimana model yang tidak memenuhi syarat evaluasi model pengukuran tidak diikutsertakan dalam analisa selanjutnya. Tahapan berikutnya adalah membandingkan nilai $Q^{2}$ dari semua model yang ada. Nilai $Q^{2}$ diperoleh dari tahapan Blindfolding, dimana tahapan ini bertujuan untuk mengevaluasi variabel laten endogen. Jika nilai 
$Q^{2}$ lebih dari 0 maka dapat dikatakan bahwa model memiliki relevansi prediktif. Tahap akhir adalah membandingkan nilai AIC, AICc, AICu, BIC, HQ dan HQc masing-masing model.

Dalam SEM-PLS terdapat dua model yaitu model pengukuran dan model struktural. Model pengukuran adalah model yang menghubungkan variabel manifest yang diobservasi dengan variabel latennya. Sedangkan model struktural menggambarkan hubungan antara variabel-variabel laten dalam model SEM-PLS. Kedua model pengukuran dan struktural dievaluasi berdasarkan hasil PLS-Algorthm, Bootstrapping dan Blindfolding. PLS-Algorthm adalah prosedur sekuensial regresi dengan tujuan mengestimasi semua elemen yang tidak diketahui dalam model jalur PLS [17]. Algoritma tersebut mengestimasi koefisien jalur dan parameter-parameter lain dari sebuah model sedemikian hingga dapat memaksimalkan variansi dari variabel endogen yang dijelaskan. Kajian [18] mendeskripsikan tahapan Bootstrapping sebagai suatu prosedur statistika nonparametrik yang memungkinkan pengujian signifikansi statistik dari berbagai hasil PLS-SEM. Blindfolding adalah prosedur iterasi penggunaaan kembali sampel yang secara sistematis menghapus titik-titik data ke-d pada indikator-indikator variabel endogen dan menyediakan estimasi dari parameter-parameter titik data yang tersisa [19], [20]. Tahapan Blindfolding dalam SEM-PLS dilakukan dengan tujuan untuk mengevaluasi nilai Stone-Geisser's $\left(Q^{2}\right)$ yang menyatakan relevaansi prediktif sebuah model.

Evaluasi model SEM-PLS dibagi menjadi 2 tahapan yaitu evaluasi model pengukuran dan evaluasi model struktural. Pada model struktural uji kolinieritas variabel-variabel laten dan tingkat siginifikansi koefisien jalur sebelum indeks PLS dianalisa. Indeks yang dimaksud yaitu nilai koefisien determinasi $R^{2}$, size effect $f^{2}$, nilai relevansi prediktif $Q^{2}$, size effect $q^{2}$ suatu model struktural [17]. Evaluasi terhadap model struktural berguna untuk memastikan seberapa baik data empiris yang ada mendukung teori atau konsep yang digunakan [18].

\subsection{Evaluasi Model Pengukuran}

Evaluasi ini bertujuan untuk memastikan bahwa model pengukuran telah valid dan reliabel. Dalam evaluasi model pengukuran, terdapat tiga indikator yang harus dievaluasi yaitu Internal Consistency, Convergent Valdity, dan Discriminant Validity. Indikator Internal Concistency adalah nilai Alpha Cronbach dan Composite Reliability dengan batas minimal keduanya 0.6 dan tidak melebihi 0.9 untuk menghindari semua variabel dan indikator mengukur fenomena yang sama [21]. Sementara nilai Average Variance Extracted (AVE) yang diharapkan melebihi dari angka > 0,5. Selanjutnya untuk kriteria Convergent Validity, dilihat Outer Loading dan AVE [20]. Nilai Outer Loading yang signifikan adalah > 0.7. Sebagai catatan, indikator dengan Outer Loading $<0.7$ tidak dapat dipertahankan hanya jika penghapusan indikator tersebut tidak meningkatkan nilai Composite Reliability. Sementara itu kriteria Discriminant Validity dilihat dari cross loading [19] dan Fornell Larcker Criterion [22]. Pada tabel Cross Loading, harus dipastikan bahwa Outer Loading setiap indikator pada suatu variabel laten harus lebih besar dari nilai Cross Loading terhadap variabel laten lain. Fornell-Larcker Criterion digunakan dengan cara membandingkan akar kuadrat AVE yang harus lebih besar dari nilai korelasi variabel-variabel laten. Jika semua kriteria evaluasi model pengukuran terpenuhi, maka tahapan selanjutnya adalah mengevaluasi model struktural.

\subsection{Evaluasi Model Struktural}

Terdapat dua hal yang diperhatikan dalam evaluasi model struktural yaitu melihat kemampuan prediktif sebuah model dan bagaimana hubungan antar variabel laten dalam model tersebut. Uji kolinieritas adalah tahap awal yang dilakukan untuk memastikan bahwa tidak terjadi kolinieritas diantara variabelvariabel laten eksogen terhadap variabel laten endogen yang sama dalam model struktural yang dibentuk. Nilai toleransi antar variabel-variabel eksogen ini tidak boleh dibawah 0,2 dan nilai VIF tidak boleh > 5 . Jika ada indikasi kolinieritas maka salah satu variabel laten eksogen harus dihapus dari model atau keduanya disatukan menjadi hanya satu variabel eksogen saja. Selanjutnya adalah mengevaluasi koefisien jalur yang menghubungkan antar variabel laten. Koefisien jalur adalah nilai estimasi yang menyatakan kekuatan hubungan antar variabel laten pada model struktural. Siginfikan atau tidaknya nilai koefisien jalur dilihat dari nilai $t$ dan $p$-value dari masing-masing jalur. Berikutnya mengevaluasi nilai koefisien determinasi $R^{2}$. Koefisien determinasi menyatakan nilai pengukuran kekuatan prediktif dari suatu model. Nilai $R^{2}$ merepresentasikan kekuatan variabel-variabel eksogen secara bersama-sama mempengaruhi 
variabel laten endogen. Nilai $R^{2}$ dikatakan substansial mulai dari 0.75 , moderate dengan batas awal 0.50 dan lemah dengan batas bawah $0.25[\mathbf{2 3}]$, [20] . Koefisien determinasi $\mathrm{R}^{2}$ dinyatakan dalam persamaan:

$$
R^{2}=1-\frac{s s_{\text {error }}}{s s_{\text {total }}}
$$

Dimana $s_{\text {error }}$ menyatakan jumlah kuadrat error dan $s_{\text {total }}$ menyatakan jumlah total kuadrat dari model. Penting dikaji bagaimana efek perubahan dari $R^{2}$ yang dinyatakan sebagai size effect $f^{2}$. Nilai ini menyatakan efek dari perubahan $R^{2}$ jika variabel eksogen tertentu diturunkan dari model. Penghapusan variabel laten eksogen ini bertujuan melihat seberapa penting variabel tersebut terhadap variabel eksogen yang dipengaruhinya. Nilai $f^{2}$ dinyatakan dengan persamaan (2) berikut.

$$
f^{2}=\frac{R_{\text {include }}^{2}-R_{\text {exclude }}^{2}}{1-R_{\text {include }}^{2}}
$$

Batas bawah nilai $f^{2}$ adalah $0.02,0.15$ dan 0.35 dengan kriteria efek variabel eksogen adalah kecil, medium dan besar [24]. Suatu variabel eksogen dikatakan tidak memiliki dampak ketika nilai $f^{2}$ kurang dari 0.02. Tahapan berikutnya adalah mengevaluasi relevansi prediktif variabel endogen pada model, yaitu nilai $Q^{2}$. Seperti halnya terdapat perubahan nilai $R^{2}$, dapat dihitung pula efek perubahan nilai $Q^{2}$ ketika salah satu variabel laten endogen tertentu diturunkan dari model. Nilai $q^{2}$ diperoleh dari persamaan (3) berikut.

$$
q^{2}=\frac{Q_{\text {include }}^{2}-Q_{\text {exclude }}^{2}}{1-Q_{\text {include }}^{2}}
$$

\subsection{Kriteria Pemilihan Model}

Pada penelitian ini, digunakan pula kriteria-kriteria diluar konteks SEM-PLS yang digunakan untuk memilih model terbaik yang dapat merepresentasikan data paling dekat dengan kondisi yang sebenarnya. Kriteria tersebut yaitu AIC (Akaike's Information Criterion) [25], AICu (Unbiased Akaike's Information Criterion) [26], AICc (Corrected Akaike's Information Criterion) [17], BIC (Bayesian Information Criteria) [27], HQ (Hannan-Quinn Criterion) dan HQc (Corrected Hannan-Quinn Criterion) [28] seperti yang disarankan [5] dan [17]. Kriteria tersebut telah banyak digunakan untuk pemilihan model dari beberapa model yang dibandingkan dimana model terbaik adalah yang memiliki nilai kriteria terkecil.

\section{HASIL DAN PEMBAHASAN}

Berdasarkan data yang diperoleh dari hasil kuesioner dibentuk model utama SEM-PLS dengan jumlah variabel manifest 40. Selanjutnya model utama dikenakan tahapan PLS-Algorithm untuk mengevaluasi nilai Outer Loading masing-masing variabel manifest. Jika nilai Outer Loading < 0.5, maka variabel tersebut dihapus dari model. Penghapusan ini dilakukan hingga setiap variabel laten memiliki nilai AVE > 0.5. Gambar 2 menampilkan model utama beserta variabel manifest dengan nilai Outer Loading $>0.5$ dan AVE masing-masing variabel laten $>0.5$. Tahapan selanjutnya adalah evaluasi model pengukuran dari model pada Gambar 2. Berdasarkan prosedur PLS-Algorithm diperoleh nilai Alpha Cronbach, Composite Reliability dan AVE seperti disajikan pada Tabel 1.

Tabel 1. Internal Concistency

\begin{tabular}{|cccc|}
\hline $\begin{array}{c}\text { Variabel } \\
\text { Laten }\end{array}$ & $\begin{array}{c}\text { Alpha } \\
\text { Cronbach }\end{array}$ & $\begin{array}{c}\text { Composite } \\
\text { Reliability }\end{array}$ & AVE \\
\hline PU & 0.807 & 0.857 & 0.500 \\
PE & 0.535 & 0.762 & 0.516 \\
RCL & 0.639 & 0.805 & 0.579 \\
IL & 0.763 & 0.834 & 0.502 \\
QL & 0.559 & 0.765 & 0.523 \\
\hline
\end{tabular}

Berdasarkan nilai pada Tabel 1 dapat disimpulkan bahwa Model Utama memenuhi syarat Internal Concistency. Walaupun nilai Alpha Cronbach variabel laten $\mathrm{PE}$ dan $\mathrm{QL}<0.6$, namun nilai Composite Reliability masih diatas 0.7 dan nilai AVE untuk setiap variabel laten $>0.5$. Selanjutnya akan dilihat hasil 
analisa untuk Convergen Validity berupa nilai Outer Loading setiap variabel manifest dan AVE masingmasing variabel laten. Nilai Outer Loading masing-masing variabel manifest yang disajikan pada Tabel 2 memperlihatkan bahwa variabel manifest pada variabel laten PE dan PU sudah diatas 0.7. Artinya model Utama telah memenuhi kriteria Convergen Validity. Sementara itu, walaupun pada variabel laten yang lain, masih terdapat variabel-variabel manifest yang terkait memiliki nilai Outer Loading $<0.7$ namun variabel tersebut masih dapat dipertahankan dalam model. Hal tersebut dikarenakan, penghapusan variabel manifest dengan Outer Loading < 0.7 tidak signifikan terhadap peningkatan nilai Composite Reliability. Nilai AVE dari setiap variabel laten dapat dilihat pada Tabel 1 dimana nilai AVE $\geq 0.5$. Dengan demikian disimpulkan bahwa pada Model Utama, kriteria Convergent Validity sudah terpenuhi. Tahapan berikutnya adalah evaluasi Discriminant Validity dengan melihat nilai Cross Coading dan Fornel-Larcker Criterion. Tabel 3 menyajikan nilai-nilai Cross Loading dari setiap variabel manifest.

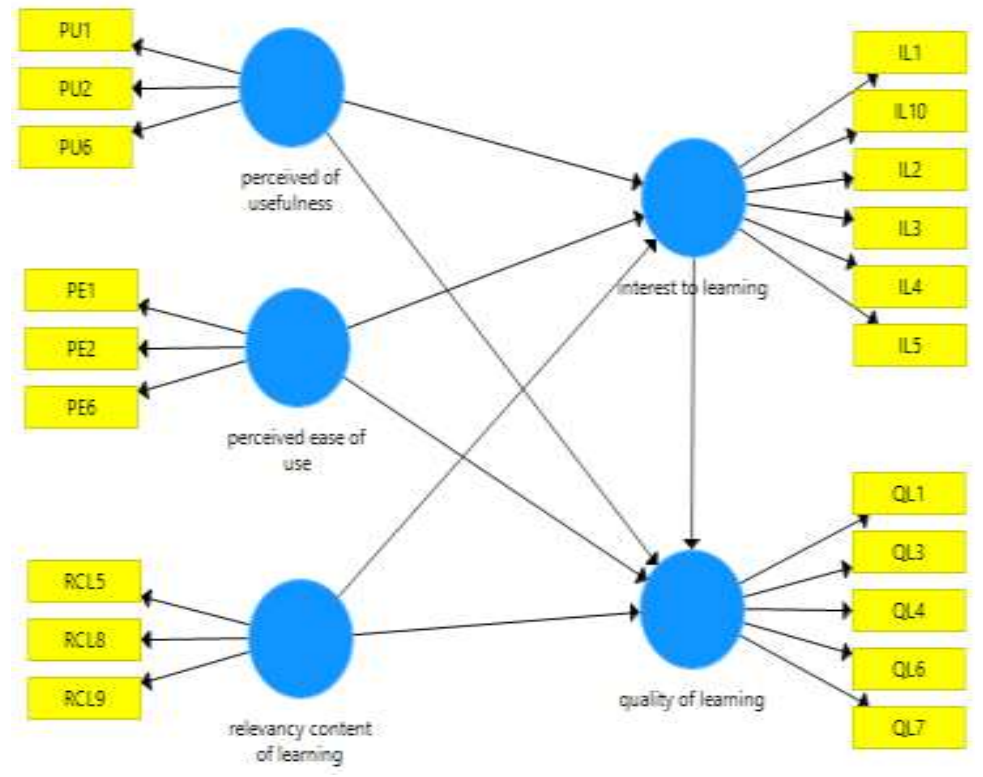

Gambar 2. Model Utama hasil tahapan PLS Algorithm

Table 2. Outer Loading

\begin{tabular}{|llllll|}
\hline VM & IL & PE & PU & QL & RCL \\
\hline IL1 & 0.681 & & & & \\
IL2 & 0.690 & & & & \\
IL3 & 0.753 & & & & \\
IL4 & 0.704 & & & & \\
IL5 & 0.657 & & & & \\
IL10 & 0.753 & & & & \\
PE1 & & 0.729 & & & \\
PE2 & & 0.703 & & & \\
PE6 & & 0.724 & & & \\
PU1 & & & 0.752 & & \\
PU2 & & & 0.790 & & \\
PU6 & & & 0.740 & & \\
QL1 & & & & 0.696 & \\
QL3 & & & & 0.738 & \\
QL4 & & & & 0.647 & \\
QL6 & & & & 0.767 & \\
QL7 & & & & 0.690 & \\
RCL5 & & & & & 0.629 \\
RCL8 & & & & & 0.825 \\
RCL9 & & & & & 0.703 \\
\hline
\end{tabular}


Nilai Cross Loading pada Tabel 3 untuk setiap variabel manifest terhadap variabel latennya lebih besar dibandingkan nilai Cross Loading terhadap variabel laten yang lain. Sementara nilai AVE untuk semua konstruk $\geq 0.5$. Sedangkan nilai akar kuadrat AVE lebih besar dari nilai korelasi variabel-variabel laten pada Fornell-Larcker Criterion seperti disajikan pada Tabel 4. Dengan demikian, Model Utama telah memenuhi asumsi Discriminant Validity. Berdasarkan evaluasi model pengukuran terhadap Model Utama, disimpulkan bahwa model pengukuran telah valid dan reliabel sehingga dapat dievaluasi lebih lanjut. Selanjutnya adalah evaluasi model struktural yang terdiri atas beberapa tahapan.

Tabel 3. Cross Loading

\begin{tabular}{|llllll|}
\hline VM & IL & PE & PU & QL & RCL \\
\hline IL1 & $\mathbf{0 . 6 8 1}$ & 0.023 & 0.423 & 0.365 & 0.217 \\
IL2 & $\mathbf{0 . 6 9 0}$ & 0.007 & 0.358 & 0.420 & 0.191 \\
IL3 & $\mathbf{0 . 7 5 3}$ & 0.053 & 0.417 & 0.525 & 0.278 \\
IL4 & $\mathbf{0 . 7 0 4}$ & 0.231 & 0.425 & 0.486 & 0.315 \\
IL5 & $\mathbf{0 . 6 5 7}$ & 0.195 & 0.376 & 0.393 & 0.211 \\
IL10 & $\mathbf{0 . 7 5 3}$ & 0.294 & 0.452 & 0.532 & 0.377 \\
PE1 & 0.178 & $\mathbf{0 . 7 2 9}$ & 0.080 & 0.194 & 0.150 \\
PE2 & 0.076 & $\mathbf{0 . 7 0 3}$ & 0.012 & 0.191 & 0.157 \\
PE6 & 0.111 & $\mathbf{0 . 7 2 4}$ & 0.119 & 0.273 & 0.284 \\
PU1 & 0.438 & 0.205 & $\mathbf{0 . 7 5 2}$ & 0.333 & 0.180 \\
PU2 & 0.445 & 0.080 & $\mathbf{0 . 7 9 0}$ & 0.367 & 0.184 \\
PU6 & 0.438 & -0.014 & $\mathbf{0 . 7 4 0}$ & 0.558 & 0.214 \\
QL1 & 0.588 & 0.320 & 0.464 & $\mathbf{0 . 6 9 6}$ & 0.494 \\
QL3 & 0.464 & 0.201 & 0.342 & $\mathbf{0 . 7 3 8}$ & 0.346 \\
QL4 & 0.408 & 0.187 & 0.384 & $\mathbf{0 . 6 4 7}$ & 0.145 \\
QL6 & 0.401 & 0.206 & 0.446 & $\mathbf{0 . 7 6 7}$ & 0.282 \\
QL7 & 0.376 & 0.141 & 0.343 & $\mathbf{0 . 6 9 0}$ & 0.365 \\
RCL5 & 0.209 & 0.097 & 0.070 & 0.277 & $\mathbf{0 . 6 2 9}$ \\
RCL8 & 0.267 & 0.282 & 0.207 & 0.416 & $\mathbf{0 . 8 2 5}$ \\
RCL9 & 0.344 & 0.209 & 0.249 & 0.342 & $\mathbf{0 . 7 0 3}$ \\
\hline
\end{tabular}

Tahapan pertama adalah menguji kolinieritas variabel-variabel laten. Hasil uji kolinieritas pada Tabel.5 menyajikan nilai Inner VIF semua kombinasi variabel laten endogen (direpresentasikan pada kolom) dan variabel eksogen yang terkait (direpresentasikan pada baris) kurang dari 5. Dengan demikian dapat disimpulkan bahwa tidak terjadi kolinieritas pada model struktural. Selanjutnya akan dianalisa nilai signifikansi koefisien jalur dari setiap jalur yang menghubungkan antar variabel-variabel laten melalui prosedur Bootstrapping.

Tabel 4. Fornel-Larcker Criterion

\begin{tabular}{|llllll|}
\hline VL & IL & PE & PU & QL & RCL \\
\hline IL & 0.707 & & & & \\
PE & 0.173 & 0.718 & & & \\
PU & 0.580 & 0.107 & 0.761 & & \\
QL & 0.649 & 0.311 & 0.567 & 0.709 & \\
RCL & 0.384 & 0.283 & 0.256 & 0.484 & 0.723 \\
\hline
\end{tabular}

Hasil olah data dengan level signifikansi 5\% disajikan pada Tabel 6. Terlihat bahwa dari 7 jalur yang menghubungkan variabel-variabel laten pada model Utama, hanya jalur PE $\rightarrow$ IL yang tidak signifikan. Artinya kemudahan penggunaan LMS (PE) tidak signifikan mempengaruhi minat belajar (IL). Koefisien jalur selain PE $\rightarrow \mathrm{IL}$ seluruhnya signifikan karena nilai $p$-value $<0.05$, dimana level signifikansi paling tinggi ada pada jalur PU $\rightarrow$ IL. Berdasarkan hasil pada Tabel 6 dapat disimpulkan bahwa variabel IL signifikan mempengaruhi variabel QL, variabel PU signifikan berpengaruh terhadap variabel IL dan QL, begitupun dengan varriabel RCL. Khusus variabel PE hanya signifikan mempengaruhi QL. Sebagai tambahan, variabel PU lebih besar pengaruhnya terhadap IL daripada terhadap QL, begitupun dengan variabel RCL yang juga lebih besar pengaruhnya terhadap Il daripada terhadap QL. 
Tabel 5. Inner VIF

\begin{tabular}{|llllll|}
\hline VL & IL & PE & PU & QL & RCL \\
\hline IL & & & & 1.660 & \\
PE & 1.089 & & & 1.093 & \\
PU & 1.071 & & & 1.509 & \\
QL & & & & & \\
RCL & 1.152 & & & 1.246 & \\
\hline
\end{tabular}

Tabel 6. Koefisien Jalur

\begin{tabular}{|llll|}
\hline Jalur & B & T stat & $p$-value \\
\hline $\mathbf{I L} \rightarrow \mathbf{Q L}$ & 0.377 & 4.302 & 0.000 \\
$\mathbf{P E} \rightarrow \mathbf{I L}$ & 0.050 & 0.604 & 0.546 \\
$\mathbf{P E} \rightarrow \mathbf{Q L}$ & 0.153 & 2.006 & 0.045 \\
$\mathbf{P U} \rightarrow \mathbf{~ I L}$ & 0.513 & 8.169 & 0.000 \\
$\mathbf{P U} \rightarrow \mathbf{Q L}$ & 0.274 & 4.074 & 0.000 \\
$\mathbf{R C L} \rightarrow \mathbf{~ I L}$ & 0.238 & 3.015 & 0.003 \\
$\mathbf{R C L} \rightarrow \mathbf{Q L}$ & 0.226 & 2.347 & 0.019 \\
\hline
\end{tabular}

Jika dilihat dari sisi variabel laten endogen, maka yang paling besar pengaruhnya terhadap variabel IL adalah PU. Di sisi lain, variabel IL memiliki pengaruh terbesar terhadap QL bila dibandingkan dengan semua variabel laten eksogen. Selanjutnya dikaji nilai koefisien determinasi dari Model Utama. Berdasarkan tahapan Bootstraping pula diperoleh nilai $R^{2}$ yang ditampilkan pada Tabel 7. Nilai koefisien determinasi dari Model Utama untuk variabel endogen IL adalah 0.398, dan 0.557 untuk variabel QL.

Tabel 7. Koefisien Determinasi

\begin{tabular}{|llll|}
\hline VM. Endogen & $R^{2}$ & T stat & $p$-value \\
\hline IL & 0.398 & 5.618 & 0.000 \\
QL & 0.557 & 11.076 & 0.000 \\
\hline
\end{tabular}

Nilai $\mathrm{R}^{2}$ merepresentasikan jumlah variansi dari variabel endogen yang dijelaskan oleh semua variabel eksogen yang terhubung dengannya yang juga menyatakan akurasi prediktif sebuah model SEMPLS. Berdasarkan Tabel 7 dapat disimpulkan bahwa nilai $R^{2}$ tergolong moderate karena dibawah 0.75 namun lebih dari 0.25 . Selanjutnya sebagai langkah mengevaluasi nilai $R^{2}$ untuk semua variabel laten endogen, dapat dilakukan dengan melihat perubahan nilai $R^{2}$ pada model. Perubahan ini dapat terjadi ketika suatu variabel eksogen tertentu dihapuskan dari model, sehingga dapat dievaluasi apakah variabel yang dihapus tersebut memiliki dampak yang substantif terhadap variabel endogen yang dipengaruhinya. Perubahan nila $R^{2}$ dinyatakan sebagai nilai vsize effect $f^{2}$ yang ditampilkan pada Tabel 8 . Berdasarkan Tabel 8 tersebut, variabel eksogen IL dan PU berdampak medium dan besar terhadap variabel endogen yang terkait dengannya jika variabel IL dan PU tersebut dihapuskan dari model.

Tabel 8. Size Effect $\mathrm{f}^{2}$

\begin{tabular}{|llc|}
\hline Jalur & $\mathrm{f}^{2}$ & Kriteria efek \\
\hline $\mathbf{I L} \rightarrow \mathbf{Q L}$ & 0.193 & Medium \\
$\mathbf{P E} \rightarrow \mathbf{~ I L}$ & 0.004 & Kecil \\
$\mathbf{P E} \rightarrow \mathbf{Q L}$ & 0.048 & Kecil \\
$\mathbf{P U} \rightarrow \mathbf{I L}$ & 0.408 & Besar \\
$\mathbf{P U} \rightarrow \mathbf{Q L}$ & 0.113 & Kecil \\
$\mathbf{R C L} \rightarrow \mathbf{~ I L}$ & 0.082 & Kecil \\
$\mathbf{R C L} \rightarrow \mathbf{Q L}$ & 0.092 & Kecil \\
\hline
\end{tabular}

Berikutnya akan dilihat kekuatan relevansi prediktif $Q^{2}$ dari Model Utama. Hasil dari prosedur Blindfolding dapat dilihat pada Tabel 9. Berdasarkan hasil pada Tabel 9, dapat disimpulkan bahwa Model Utama memiliki relevansi prediktif untuk variabel endogen IL dan QL karena nilai $Q^{2}>0$. Artinya model jalur pada Model Utama cukup baik memprediksi nilai-nilai yang diamati. Seperti pada $R^{2}$, evaluasi 
terhadap dampak relatif dari $Q^{2}$ dilakukan dengan menghitung nilai $q^{2}$. Nilai $q^{2}$ digunakan untuk melihat apakah variabel IL dan QL memiliki dampak yang relatif kecil, moderate ataupun besar jika IL atau QL dihapuskan dari model. Prosedur yang harus dilakukan yaitu dengan cara mengestimasi ulang Model Utama jika IL dihapus sehingga diperoleh nilai $Q^{2}$ yang baru untuk QL dan sebaliknya jika QL dihapus dari model maka akan didapatkan nilai $Q^{2}$ yang baru untuk IL. Nilai-nilai $Q^{2}$ baru disebut sebagai nilai

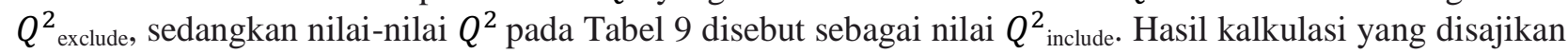
pada Tabel 9, menunjukkan bahwa nilai $q^{2}$, relatif kecil karena kurang dari 0.15 namun lebih dari 0.02 . Dengan demikian, berdasarkan hasil evaluasi model struktural dapat dikatakan bahwa Model Utama memiliki nilai $R^{2}$ yang moderate dan relevansi prediktif dengan $Q^{2}>0$.

Tabel 9. Relevansi Prediktif dan Size Effect $q^{2}$
\begin{tabular}{|ccc|}
\hline VM. Endogen & $Q^{2}$ & $q^{2}$ \\
\hline IL & 0.164 & 0.0024 \\
QL & 0.237 & 0.0432 \\
\hline
\end{tabular}

Selanjutnya 16 model alternatif dibentuk berdasarkan Model Utama yang telah dievaluasi model pengukuran dan strukturalnya. Jalur hubungan model struktural dari 16 model alternatif diperoleh dari konfigurasi hubungan dari Model Utama. Sebagai tambahan, variabel-variabel manifest yang digunakan pada ke-16 model alternatif tersebut adalah variabel -variabel manifest hasil PLS-Algorithm awal seperti pada Gambar 2. Pada Gambar 3 disajikan model struktural dengan jalur dari Model Utama yang sudah dinomori.

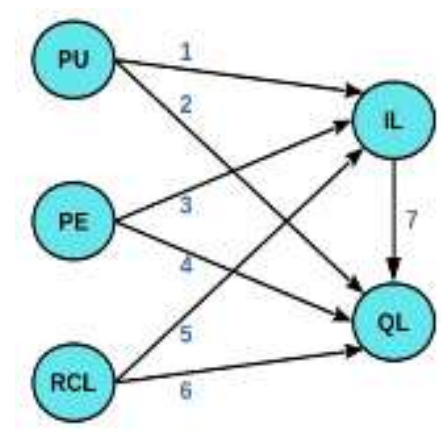

\section{Gambar 3. Model Utama}

Pada Tabel 10, disajikan jalur hubungan antar variabel-variabel laten pada model alternatif. Model alternatif yang telah dibentuk, kemudian dikenakan tahapan PLS-Algorithm untuk memastikan bahwa 16 model tersebut valid dan reliabel. Berdasarkan hasil tahapan PLS-Algorithm terdapat 2 model alternatif yaitu model $\mathrm{E}_{2}$ dan $\mathrm{F}_{2}$, yang tidak dapat dianalisa lebih lanjut karena tidak memenuhi kriteria Convergent Validity. Maka hanya terdapat 14 model yang akan dievaluasi menggunakan prosedur selanjutnya. Berdasarkan prosedur Bootsrapping, 14 model alternatif tersebut memiliki nilai 62 koefisien jalur yang signifikan dari total 72 jalur. Artinya $13.89 \%$ jalur yang ada pada model struktural pada keempat belas model aternatif tidak menggambarkan hubungan yang signifikan. Dari semua model alternatif, variabel PE adalah variabel yang paling sering tidak signifikan mempengaruhi variabel laten yang lain.

Tabel 10. Jalur Hubungan Variabel Laten

\begin{tabular}{|cccc|}
\hline Model & Nomor Jalur & Model & Nomor Jalur \\
\hline Utama & $1,2,3,4,5,6,7$ & $\mathrm{E}_{1}$ & $1,3,5,6,7$ \\
$\mathrm{~A}_{1}$ & $1,2,3,4,6,7$ & $\mathrm{E}_{2}$ & $2,4,5,6,7$ \\
$\mathrm{~A}_{2}$ & 1.2 .3 .4 .5 .7 & $\mathrm{~F}_{1}$ & $1,4,5,6,7$ \\
$\mathrm{~B}_{1}$ & $1,3,4,5,6,7$, & $\mathrm{F}_{2}$ & $2,3,5,6,7$ \\
$\mathrm{~B}_{2}$ & $2,3,4,5,6,7$ & $\mathrm{G}_{1}$ & $1,3,6,7$ \\
$\mathrm{C}_{1}$ & $1,2,3,5,6,7$ & $\mathrm{G}_{2}$ & $1,4,6,7$ \\
$\mathrm{C}_{2}$ & $1,2,4,5,6,7$ & $\mathrm{H}_{1}$ & $2,4,5,7$ \\
$\mathrm{D}_{1}$ & $1,2,3,6,7$ & $\mathrm{H}_{2}$ & $2,3,5,7$ \\
$\mathrm{D}_{2}$ & $1,2,4,6,7$ & & \\
\hline
\end{tabular}


Selanjutnya, signifikan tidaknya pengaruh variabel PE, PU dan RCL terhadap IL dan QL pada model $\mathrm{B}_{2}$ dan $\mathrm{C}_{2}$ dapat dilihat melalui nilai koefisien jalur hubungan yang disajikan pada Tabel 11. Secara umum setiap jalur hubungan pada model, signifikan dengan $p$-value $<0.05$. Hanya jalur hubungan PE $\rightarrow$ IL pada model $\mathrm{B}_{2}$ yang tidak memenuhi level signifikansi $5 \%$. Seluruh jalur hubungan variabel laten pada model $\mathrm{C}_{2}$ signifikan, dimana PU paling signifikan mempengaruhi IL. Sementara itu, walaupun p-value $<0.05$, variabel PE memiliki nilai koefisien jalur paling rendah. Jadi, variabel kemudahan penggunaan LMS (PE) adalah variabel paling tidak signifikan pengaruhnya terhadap minat belajar (IL) dan kualitas hasil belajar (QL) dalam kasus ini. Berdasarkan koefisien jalur Model Utama pada Tabel 6, dan koefisien jalur $\mathrm{C}_{2}$ pada Tabel 1, PU dan RCL signifikan berpengaruh terhadap IL dan QL. Sementara berdasarkan koefisien jalur pada model $\mathrm{C}_{2}$, RCL berpengaruh terhadap IL dan QL, dan PU hanya berpengaruh pada QL, hal ini karena tidak terdapat jalur hubungan variabel PU ke IL.

Tabel 11. Koefisien Jalur Model $\mathrm{B}_{2}$ dan $\mathrm{C}_{2}(\mathrm{QL})$

\begin{tabular}{|cccccccc|}
\hline Jalur & $\begin{array}{c}\text { Koefisien } \\
\text { Jalur } \\
\text { Model } \mathbf{B}_{2}\end{array}$ & $\begin{array}{c}\text { T } \\
\text { stat }\end{array}$ & P value & Jalur & $\begin{array}{c}\text { Koefisien } \\
\text { Jalur } \\
\text { Model } \mathbf{C}_{\mathbf{2}}\end{array}$ & $\begin{array}{c}\text { T } \\
\text { stat }\end{array}$ & P value \\
\hline $\mathrm{IL} \rightarrow \mathrm{QL}$ & 0,364 & 4,003 & 0,000 & $\mathrm{IL} \rightarrow \mathrm{QL}$ & 0,378 & 4,300 & 0,000 \\
$\mathrm{PE} \rightarrow \mathrm{QL}$ & 0,156 & 2,028 & 0,043 & $\mathrm{PE} \rightarrow \mathrm{QL}$ & 0,157 & 2,157 & 0,031 \\
$\mathrm{PU} \rightarrow \mathrm{QL}$ & 0,300 & 4,417 & 0,000 & $\mathrm{PU} \rightarrow \mathrm{QL}$ & 0,274 & 4,133 & 0,000 \\
$\mathrm{RCL} \rightarrow \mathrm{QL}$ & 0,220 & 2,351 & 0,019 & $\mathrm{RCL} \rightarrow \mathrm{QL}$ & 0,223 & 2,319 & 0,020 \\
$\mathrm{PE} \rightarrow \mathrm{IL}$ & 0,072 & 0,825 & 0,409 & $\mathrm{RCL} \rightarrow \mathrm{IL}$ & 0,252 & 3,524 & 0,000 \\
$\mathrm{RCL} \rightarrow \mathrm{IL}$ & 0,367 & 4,191 & 0,000 & $\mathrm{PU} \rightarrow \mathrm{IL}$ & 0,515 & 8,058 & 0,000 \\
\hline
\end{tabular}

Tahapan berikutnya, nilai prediktif relevansi dari 14 model dibandingkan dengan model Utama. Pada Tabel 12 disajikan hasil Blindfolding dari 15 model tersebut. Berdasarkan evaluasi terhadap nilai $Q^{2}$, bahwa Model Utama dan model $\mathrm{C}_{2}$ memiliki pasangan nilai $Q^{2}$ untuk variabel laten IL dan QL yang paling besar. Walaupun pada model alternatif $\mathrm{B}_{2}$, nilai $Q^{2}$ dari variabel endogen $\mathrm{QL}$ adalah 0.241 namun $Q^{2}$ nilai variabel endogen IL sangat kecil yaitu 0,057 . Sehingga berdasarkan nilai $\mathrm{Q}^{2}$, Model Utama dan model $\mathrm{C}_{2}$ dapat dinyatakan lebih baik dari semua model alternatif lain pada kasus ini. Selanjutnya indeks lain yang digunakan untuk memilih model SEM-PL terbaik adalah nilai AIC, AICu, AICc, BIS, HQ dan HQc dari setiap model yang ada [17]. Model yang dipilih adalah model dengan indeks kriteria yang paling kecil. Berdasarkan kriteria AIC, AICu, AICc, BIC, HQ dan HQc pada Tabel 13 dan 14, diperoleh hasil bahwa model $\mathrm{C}_{2}$ memiliki kriteria lebih baik pada variabel endogen IL.

Tabel 12. Perbandingan $Q^{2}$

\begin{tabular}{|ccc|}
\hline Model & \multicolumn{2}{c|}{$Q^{2}$} \\
\cline { 2 - 3 } & IL & $\mathbf{Q L}$ \\
\hline Model Utama & $\mathbf{0 . 1 6 4}$ & $\mathbf{0 . 2 3 7}$ \\
$\mathrm{A}_{1}$ & 0.147 & 0.237 \\
$\mathrm{~A}_{2}$ & 0.164 & 0.224 \\
$\mathrm{~B}_{1}$ & 0.162 & 0.216 \\
$\mathrm{~B}_{2}$ & 0.057 & 0.241 \\
$\mathrm{C}_{1}$ & 0.164 & 0.230 \\
$\mathrm{C}_{2}$ & $\mathbf{0 . 1 6 4}$ & $\mathbf{0 . 2 3 7}$ \\
$\mathrm{D}_{1}$ & 0.147 & 0.230 \\
$\mathrm{D}_{2}$ & 0.143 & 0.237 \\
$\mathrm{E}_{1}$ & 0.162 & 0.209 \\
$\mathrm{~F}_{1}$ & 0.162 & 0.217 \\
$\mathrm{G}_{1}$ & 0.144 & 0.209 \\
$\mathrm{G}_{2}$ & 0.140 & 0.216 \\
$\mathrm{H}_{1}$ & 0.057 & 0.230 \\
$\mathrm{H}_{2}$ & 0.059 & 0.214 \\
\hline
\end{tabular}

Sementara itu, model $\mathrm{B}_{2}$ memiliki kriteria lebih baik dari model yang lain pada variabel QL, walaupun berdasarkan kriteria nilai $\mathrm{HQ}$ model $\mathrm{H}_{1}$ lebih baik dari model yang lain. Namun secara umum, model $\mathrm{B}_{2}$ dan $\mathrm{C}_{2}$ yang paling banyak memenuhi kriteria model terbaik. Dengan demikian dapat disimpulkan bahwa 
Model Utama, model $\mathrm{B}_{2}$ dan $\mathrm{C}_{2}$ dapat digunakan untuk melihat pengaruh LMS (PE, PU) dan konten pembelajaran (RCL) di dalamnya terhadap minat (IL) dan kualitas hasil belajar (QL) mahasiswa.

Pada penelitian ini, diperoleh pula hasil bahwa hanya model $\mathrm{C}_{2}$ yang memenuhi syarat sebagai model terbaik berdasarkan kriteria $Q^{2}$ dan kriteria $\mathrm{AIC}$, $\mathrm{AICu}$, AICc, BIC, HQ dan $\mathrm{HQc}$ secara bersamaan. Namun demikian bukan berarti model $\mathrm{C}_{2}$ ini adalah satu-satunya model yang dapat digunakan untuk menggambarkan hubungan variabel-variabel laten pada kasus pemanfaatan LMS dalam pembelajaran Matematika Diskrit. Hasil penelitian ini sejalan dengan hasil simulasi penggunaan kriteria $\mathrm{Q}^{2}$ [4], AIC, $\mathrm{AICu}, \mathrm{AICc}, \mathrm{BIC}, \mathrm{HQ}$, dan HQc [5] terhadap model-model SEM-PLS. Sebagai bahan kajian lebih lanjut, penambahan kriteria nilai GM (Geweke-Messe) dalam pemilihan model SEM-PLS dapat dilakukan karena tingkat keakuratan dari GM dalam memilih model terbaik [29].

Tabel 13. Kriteria Pemilihan Model (IL)

\begin{tabular}{|c|cccccc|}
\hline \multirow{2}{*}{ Model } & \multicolumn{7}{c|}{ Interest to Learning (IL) } \\
\cline { 2 - 7 } & $\mathbf{A I C}$ & $\mathbf{B I C}$ & $\mathbf{A I C u}$ & $\mathbf{H Q}$ & $\mathbf{A I C c}$ & HQc \\
\hline Utama & -48.255 & -37.490 & -44.180 & -43.890 & 63.327 & -43.169 \\
$\mathrm{~A}_{1}$ & -41.627 & -33.553 & -38.585 & -38.353 & 69.757 & -37.907 \\
$\mathrm{~A}_{2}$ & -48.670 & -37.905 & -44.595 & -44.305 & 62.912 & -43.584 \\
$\mathrm{~B}_{1}$ & -47.770 & -37.004 & -43.694 & -43.404 & 63.813 & -42.683 \\
$\mathrm{~B}_{2}$ & -13.316 & -5.242 & -10.274 & -10.041 & 98.069 & -9.595 \\
$\mathrm{C}_{1}$ & -48.699 & -37.934 & -44.624 & -44.334 & 62.883 & -43.623 \\
$\mathrm{C}_{2}$ & $\mathbf{- 4 9 . 7 9 0}$ & $\mathbf{- 4 1 . 7 1 6}$ & $\mathbf{- 4 6 . 7 4 8}$ & $\mathbf{- 4 6 . 5 1 6}$ & $\mathbf{6 1 . 5 9 5}$ & $\mathbf{- 4 6 . 0 7 0}$ \\
$\mathrm{D}_{1}$ & -42.165 & -34.091 & -39.123 & -38.890 & 69.220 & -38.444 \\
$\mathrm{D}_{2}$ & -41.524 & -36.142 & -39.506 & -39.341 & 69.704 & -39.106 \\
$\mathrm{E}_{1}$ & -48.149 & -37.383 & -44.073 & -43.783 & 63.434 & -43.063 \\
$\mathrm{~F}_{1}$ & -49.415 & -41.341 & -46.373 & -46.140 & 61.970 & -45.695 \\
$\mathrm{G}_{1}$ & -41.365 & -33.291 & -38.323 & -38.091 & 70.019 & -37.645 \\
$\mathrm{G}_{2}$ & -41.035 & -35.653 & -39.017 & -38.853 & 70.193 & -38.617 \\
$\mathrm{H}_{1}$ & -15.434 & -10.052 & -13.416 & -13.252 & 95.794 & -13.016 \\
$\mathrm{H}_{2}$ & -14.557 & -6.483 & -11.515 & -11.283 & 96.828 & -10.837 \\
\hline
\end{tabular}

Tabel 14. Kriteria Pemilihan Model (QL)

\begin{tabular}{|ccccccc|}
\hline \multirow{2}{*}{ Model } & \multicolumn{7}{c|}{ Quality of Learning (QL) } \\
\cline { 2 - 7 } & AIC & BIC & AICu & HQ & AICc & HQc \\
\hline Utama & -79.672 & -66.216 & -74.554 & -74.215 & 32.151 & -73.154 \\
$\mathrm{~A}_{1}$ & -79.989 & -66.553 & -74.871 & -74.532 & 31.834 & -73.471 \\
$\mathrm{~A}_{2}$ & -71.902 & -61.137 & -67.827 & -67.536 & 39.681 & -66.816 \\
$\mathrm{~B}_{1}$ & -71.460 & -60.695 & -67.385 & -67.095 & 40.122 & -66.374 \\
$\mathrm{~B}_{2}$ & $\mathbf{- 8 2 . 0 0 7}$ & $\mathbf{- 6 8 . 5 5 0}$ & $\mathbf{- 7 6 . 8 8 8}$ & -76.549 & $\mathbf{2 9 . 8 1 7}$ & $\mathbf{- 7 5 . 4 8 9}$ \\
$\mathrm{C}_{1}$ & $-\mathbf{7 6 . 4 1 1}$ & -65.645 & -72.336 & -72.045 & 35.172 & -71.325 \\
$\mathrm{C}_{2}$ & -79.980 & -66.523 & -74.862 & -74.523 & 31.843 & -73.462 \\
$\mathrm{D}_{1}$ & -76.783 & -66.018 & -72.708 & -72.417 & 34.799 & -71.697 \\
$\mathrm{D}_{2}$ & -80.310 & -66.854 & -75.192 & -74.853 & 31.513 & -73.792 \\
$\mathrm{E}_{1}$ & -68.771 & -60.697 & -65.729 & -65.497 & 42.614 & -65.051 \\
$\mathrm{~F}_{1}$ & -71.757 & -60.992 & -67.682 & -67.392 & 39.825 & -66.671 \\
$\mathrm{G}_{1}$ & -69.100 & -61.026 & -66.068 & -65.826 & 42.285 & -65.380 \\
$\mathrm{G}_{2}$ & -72.047 & -61.282 & -67.972 & -67.682 & 39.535 & -66.961 \\
$\mathrm{H}_{1}$ & -74.995 & -64.229 & -70.920 & $\mathbf{- 7 9 . 6 2 9}$ & 36.588 & -69.909 \\
$\mathrm{H}_{2}$ & -67.106 & -59.032 & -64.064 & -63.831 & 44.279 & -63.386 \\
\hline
\end{tabular}

\section{KESIMPULAN}

Berdasarkan hasil dan pembahasan dari penelitian ini dapat disimpulkan bahwa dalam konteks SEM-PLS, berdasarkan krtiteria relevansi prediktif $Q^{2}$, Model Utama dan model $\mathrm{C}_{2}$ adalah model terbaik jika dibandingkan dengan 13 model alternatif lain. Namun, jika pemilihan model terbaik dilakukan berdasarkan kriteria AIC, AICu, AICc, BIC, HQ dan HQc maka terdapat dua model alternatif terbaik yaitu model $\mathrm{C}_{2}$ dan $\mathrm{B}_{2}$. Dengan demikian, Model Utama, model $\mathrm{C}_{2}$ dan $\mathrm{B}_{2}$ adalah pilihan model yang dapat digunakan untuk menggambarkan dan mengevaluasi hubungan variabel laten eksogen yaitu Perceived of 
Usefulness (PU), Perceived Ease of Use (PE), Relevancy Content of Learning (RCL) yang mempengaruhi variabel laten endogen yaitu Interest to Learning (IL) dan Quality of Learning (QL) pada kasus pemanfaatan LMS sebagai sistem pendukung dalam proses pembelajaran Matematika Diskrit secara lebih baik.

\section{UCAPAN TERIMA KASIH}

Terima kasih kepada Kemenristekdikti atas dukungan dana hibah Penelitian Dosen Pemula Tahun Pelaksanaan 2018

\section{DAFTAR PUSTAKA}

[1] Heinz-Theo Wagner, Daniel Beimborn, and Tim Weitzel, "How Social Capital Among Information Technology and Business Units Drives Operational Alignment and IT Business Value," Journal of Management Information Systems, vol. 31, no. 1, pp. 241-272, 2014.

[2] T. A Sykes, "Support Structures and Their Impacts on Employee Outcomes: A Longitudinal Field Study of an Enterprise Sistem Implementation," MIS Quarterly, vol. 39, no. 2, pp. 437-495, 2015.

[3] L Xue, C Zhang, H Ling, and X Zhao, "Risk Mitigation in Supply Chain Digitization: Sistem Modularity and Information Technology Governance," Journal of Management Information Systems, vol. 30, no. 1, pp. 325-352, 2013.

[4] P.N Sharma and K.H Kim, "Model Selection in Information Sistem Research Using Partial Least Square-Based Structural Equation Modeling," in Proceedings of 33rd International Conference on Information Systems, Orlando, 2012, pp. 1-12.

[5] P.N Sharma, M Sarstedt, G Shmueli, K.H Kim, and K.O Thiele, "“Model selection in MIS research using PLSSEM," Working paper, 2018.

[6] F.D Davis, R.P Bagozzi, and P.R Warshaw, "User Acceptane of Computer Technology : A Comparison of Two Theoritical Models," Management Science, vol. 35, no. 8, pp. 982-1003, 1989.

[7] W.H Delone and E.R McLean, "Information System Success : The Quest of Dependent Variable," Information System Research, vol. 3, no. 1, pp. 60-95, 1992.

[8] S Ghazal, H Aldowah, I Umar, and B Bervel, "Acceptance and Staisfication of learning Management System Enabled Blended Learning Based on a Modified Delon-McLean Information System Success Model," Internationalmof Information technology Project Manegement, vol. 9, no. 3, pp. 52-71, 2018.

[9] Sean.B Eom, "Effects og LMS, Self Efficacy, Self Regulated Learning on LMS Effectiveness in Business Education," Journal of International Education in Business, vol. 5, no. 2, pp. 129-144, 2012.

[10] M Firat, "Determining The Effects of LMS LEarning Behaviors on Academic Achievement in A Learning Analytic Perspective," Journal Information Technology Education Research, vol. 15, pp. 075-087, 2016.

[11] J Meenakumari, B Anthony, and M Vinay, "Measuring The Usage of LMS in Higher Education Institution : An Analysis," International Journal of Advanced Computational Engineering and Networking, vol. 1, no. 2, pp. 6165, 2013.

[12] A Altunoglu, "Initial Perception of Open Higher Education Students with Learner Management System," vol. 18, no. 3, pp. 96-104, 2017.

[13] M.G Marković, B Kliček, and D.P Vukovac, "The Effects of Multimedia Learning Materials Quality on Knowledge Acquisition," in 23rd International COnfrerence on Information SYstem Development (ISD), Kroasia, 2014, pp. 140-149.

[14] Gali Naveh, Dorit Tubin, and Nava Pliskin, "Student satisfaction with learning management systems: a lens of critical success factors," Technology, Pedagogy and Education, vol. 21, no. 3, pp. 337-350, 2012.

[15] L.S Green, F.A Inan, and B Denton, "Examination of Factors Impacting Student Satisfaction with a New Learning Management System," Turkish Online Journal of Distance Education, vol. 13, no. 3, pp. 189-197, 2012.

[16] B.N Potter and C.G Johnston, "The Effect of Interactive On-line Learning Systems on Student Learning Outcomes in Accounting," Journal of Accounting Education, vol. 24, no. 1, pp. 16-34, 2006.

[17] J.F Hair, G.T.M Hult, C.M Ringle, and M Sarstedt, Primer on Partial Least Squares Structural Equation Modeling (PLS-SEM), Kedua ed. California: Sage Publication, 2017.

[18] J.F Hair, C.M Ringle, and M Sarstedt, "Partial Least Square Struktural Equation Modeling : Rigorous Applications, Better Resuts and Higher Acceptance," Long Range Planning, vol. 46, no. 1-2, pp. 1-12, 2013. 
[19] W.W Chin, "The Partial Least Square Approach for Structural Equation Modeling," in Marcoulides, G.A (ed) Modern Methods for Business Research. London: Lawrence Erlbaum Associates, 1998, pp. 295-336.

[20] J Hanseler, C.M Ringle, and R.R Sinkovics, "The Use of Partial Least Squares Structural Equation Modeling (PLS-SM)," Advance in International Marketing, vol. 20, pp. 277-319, 2009.

[21] J.F Hair, T.M Hult, C.M Ringle, and M Sarstedt, A Primer on Partial Least Squares Structural Equation Modeling (PLS-SEM). Los Angeles: SAGE, 2014.

[22] C Fornell and D.F Larcker, "Evaluating Structural Equation Models with Unobserable Variables and Measurement Error," Journal of Marketing Research, vol. 18, no. 1, pp. 39-50, 1981.

[23] J.F Hair, M Sarstedt, and C.M Ringle, "PLS-SEM : Indeed A Siver Bullet," Journal of Marketing Theory and Practice, vol. 19, no. 2, pp. 139-152, 2011.

[24] J Cohen, Statistical Power Analysis for the Behavioral Science. New York: Psychology Press, 1988.

[25] H Akaike, "A New Look at The Statsitical Model Indetification," IEEE Transaction on Automatic Control, vol. 19, no. 6, pp. 716-723, 1974.

[26] A McQuarrie and C Tsai, Regression and Time Series Model Selection. Singapore: World Scientific Publishing, 1998.

[27] Gideon Schwarz, "Schwarz, G, "Estimating The Dimension of a Model," Ann. Statist," The Annals of Statistics, vol. 6, no. 2, pp. 461-464, 1978.

[28] E.J Hannan and B.G Quinn, "The Determination of the Order of an Autoregression," Journla of The Royal Statistical Society. Series B (Methodological), vol. 41, no. 2, pp. 190-195, 1979.

[29] Pratyush Nidhi Sharma, Marko Sarstedt, Galit Shmuel, Kevin H Kim, and Kair Oliver Thiele, "PLS-Based Model Selection: The Role of Alternative Explanations in Information Systems Research," Journal of the Association for Information Systems, vol. 20, no. 4, pp. 346-397, 2019. 
